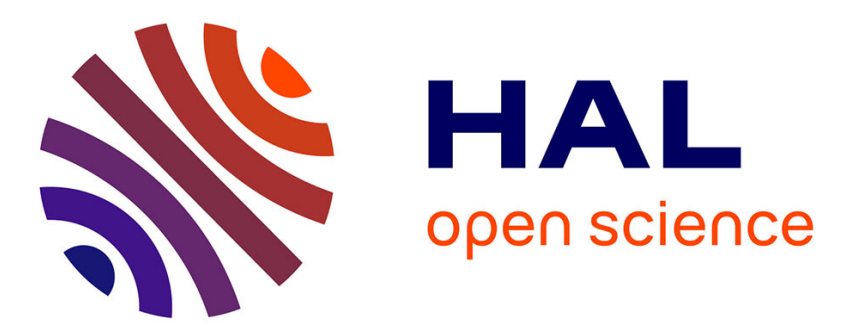

\title{
Price dynamics, financial fragility and aggregate volatility
}

Antoine Mandel, Simone Landini, Mauro Gallegati, Herbert Gintis

\section{To cite this version:}

Antoine Mandel, Simone Landini, Mauro Gallegati, Herbert Gintis. Price dynamics, financial fragility and aggregate volatility. Journal of Economic Dynamics and Control, 2015, 51, pp.257-277. 10.1016/j.jedc.2014.11.001 . halshs-01152302

\section{HAL Id: halshs-01152302 https://shs.hal.science/halshs-01152302}

Submitted on 15 May 2015

HAL is a multi-disciplinary open access archive for the deposit and dissemination of scientific research documents, whether they are published or not. The documents may come from teaching and research institutions in France or abroad, or from public or private research centers.
L'archive ouverte pluridisciplinaire HAL, est destinée au dépôt et à la diffusion de documents scientifiques de niveau recherche, publiés ou non, émanant des établissements d'enseignement et de recherche français ou étrangers, des laboratoires publics ou privés. 


\title{
Price dynamics, financial fragility and aggregate volatility ${ }^{*}$
}

\author{
Antoine Mandel, Simone Landini, Mauro Gallegati, Herbert Gintis**
}

February 21, 2015

\begin{abstract}
Within a general equilibrium framework à la Long and Plosser (1983), we investigate the dynamics emerging from the interactions of households and firms that are adaptive price setters and financially constrained. Adaptive price-setting behavior induces micro founded out-of-equilibrium dynamics along which agents become heterogeneous in terms of prices and wealth. The stringency of the financial constraints determine the regime into which the model settles: either an equilibrium one or a disequilibrium one conductive to financial fragility and aggregate volatility. In this setting, we investigate how the structure of the production network affects the emergence of aggregate volatility from micro-level price and financial shocks, hence providing a dynamical counterpart to recent results of Acemoglu and al (2012).
\end{abstract}

Key Words: Agent-Based Modeling, General Equilibrium, Financial Fragility, Macroeconomic Volatility.

JEL Codes: C63 C67 E32

*We are grateful to Carlo Jaeger, Andreas Karpf, Mauro Napoletano and to seminar participants at the INET False Dichotomies Conference, the University of Nice, the WEHIA 2013 and the CRISIS project meeting in Paris for their comments and suggestions. We thank Binghuan Lin for excellent research assistance. Financial support under Institute for New Economic Thinking grant INO1200022 and EU FP7 project SIMPOL is gratefully acknowledged.

${ }^{\dagger}$ The source code for simulations reported in this paper is available online at https://sites.google.com/site/antoinedavidmandel/codes.

$\ddagger$ Paris School of Economics-Université Paris 1 Panthéon-Sorbonne

$\S$ corresponding author: antoine.mandel@univ-paris1.fr

ฯ Socioeconomic Research Institute of Piedmont

\| Università Politecnica delle Marche

**European Central University and Santa-Fe Institute 


\section{Introduction}

In a recent paper, Acemoglu et al. (2012) investigate the influence of the topology of production networks on the transmission of shocks and the build-up of macroeconomic volatility. They show that in the presence of intersectoral inputoutput linkages, microeconomic idiosyncratic shocks do not necessarily average out but may lead to aggregate fluctuations. They also provide quantitative estimates which indicate that these fluctuations could be of the same order of magnitude as those of US GDP.

These results potentially represent major advances in our understanding of the origins of macro-economic fluctuations. Yet, the approach used by Acemoglu and co-authors is essentially static and asymptotic: "aggregate volatility" is measured through a comparative static analysis of the level of GDP at equilibrium when the number of sectors tends towards infinity. In this equilibrium perspective, the actual mechanics of crisis and, more generally, the temporal dimension are absent.

The aim of this paper is fill this gap by introducing a micro-founded dynamic model in which the emergence and the propagation of shocks are endogenous, the unfolding of crisis can actually be observed and where aggregate volatility materializes in a truly dynamic sense. This mainly implies shifting from a framework where adjustment to equilibrium is assumed to take place instantaneously to a framework where convergence to or divergence from equilibrium is determined endogenously. The efforts of general equilibrium theory in that direction were based on centralized price adjustment processes and almost entirely stopped by the impossibility results put forward in the Sonnenschein-MantelDebreu theorem. We take here a different route and use agent-based modeling to generate out-of-equilibrium dynamics via the simulation of the interactions of boundedly rational and heterogeneous agents (see LeBaron and Tesfatsion, 2008 , for an introduction to agent-based modeling).

More precisely, we place ourselves in the general equilibrium framework à la Long and Plosser (1983) considered by Acemoglu et al. (2012) and define out-ofequilibrium dynamics through the interactions of agents that are adaptive price setters and whose production is financially constrained. The assumption that agents are adaptive price setters is based on recent work of ours in which we show that evolutionary learning of heterogeneous price setting agents provides a viable alternative to the Walrasian tâtonnement (see Gintis, 2007; Gintis and Mandel, 2012). The assumption that agents are financially constrained is based on the work of Greenwald and Stiglitz (1993) emphasizing the real impacts of asymmetric information on credit markets and is here taken as an endogenous route to disequilibrium: financial constraints on production can impair the local functioning of markets and hence generate endogenously micro-economic shocks from which aggregate volatility can emerge. Moreover, as in previous work on financial fragility by Delli Gatti, Gallegati and co-authors (most recently Delli Gatti et al., 2010; Battiston et al., 2012a), the presence of credit networks and the positive feedback between financial fragility and financial constraints foster the propagation of financial shocks. As a whole, our model accounts 
both for processes of convergence towards equilibrium and for the endogenous creation of shocks, disequilibrium and aggregate volatility. The model is stockflow consistent and dynamically complete.

The results we obtain in this setting confirm those of Acemoglu et al. (2012) as far as the influence of the topology of the production network on aggregate volatility is concerned. Yet, we also identify a strong connection between disequilibrium and aggregate volatility, which is, by definition, absent in the equilibrium model of Acemoglu and co-authors. In our setting, it is out-of-equilibrium, that is when prices move away from their general equilibrium values and markets do not clear, that crisis and aggregate volatility materialize.

Disequilibrium itself is brought about by financial constraints which impair the competitive functioning of markets and propagate shocks through credit networks. Establishing this link between financial fragility and disequilibrium is another contribution of the paper as it clarifies the relationships between agent-based models and general equilibrium. Hence the paper contributes both to the literature on the origins of aggregate fluctuations and to the theoretical foundations of agent-based modeling.

There is a substantial literature on the origin of aggregate fluctuations that investigate whether independent idiosyncratic shocks can generate aggregate volatility. The pioneering contribution by Bak et al. (1993) looks at selforganized criticality in production networks and show that independent shocks fail to cancel in the aggregate if interactions are local and technologies nonconvex. Gabaix (2011) arrives at a similar conclusion in a model where the distribution of firms' size is fat-tailed. He moreover shows that the idiosyncratic movements of the largest 100 firms in the United States appear to explain about one-third of variations in output growth. Yet, the models by Bak and Gabaix focus on the production sector and therefore lack macro-economic closure and potential feedback mechanisms brought about e.g by variations in demand.

The "equilibrium" contributions by Acemoglu et al. (2012) and its precursors such as (Horvath, 1998, 2000) and Dupor (1999) are more complete from this perspective. Yet these authors consider aggregate volatility as an equilibrium response to exogenous productivity shocks in a static framework whereas we emphasize the role of disequilibrium and the endogenous origin of shocks. Hence, with respect to the equilibrium literature, our contribution is to ground existing results on the non-diversification of shocks in a dynamical setting with heterogenous interacting agents and to allow for the endogenous generation and propagation of shocks via bankruptcies, defaults and network-based financial accelerator mechanisms (see Delli Gatti et al., 2010) thanks to the introduction of out-of-equilibrium dynamics and of an explicit financial structure. In particular, we address some of the research questions put forward in Acemoglu et al. (2012): "another important area for future research is a systematic analysis of the relationship between the structure of financial networks and the extent of contagion and cascading failures."

The relation between disequilibrium and aggregate fluctuations is on another hand central to the agent-based literature (see among others Dosi et al., 2010; Dawid et al., 2011; Mandel et al., 2010; Wolf et al., 2013). For exam- 
ple, in a series or recent contribution (see Napoletano et al., 2012; Dosi et al., 2013), Dosi and co-authors emphasize how income inequality and/or the lack of redistributive fiscal policies destabilize the economy, impair growth and employment, accentuate volatility. Our own contribution is more closely related to the work of Delli Gatti, Gallegati and co-authors (see Delli Gatti et al., 2005, and further references) emphasizing scaling laws and financial fragility as sources of macroeconomic volatility. Yet, these agent-based models generally have one or two aggregate sectors and can't therefore investigate the influence of intersectoral linkages that is central to Acemoglu et al. (2012) and to our analysis. A notable exception is Battiston et al. (2007) who consider the spreading of shocks in a hierarchical production structure where firms are linked both by technological and trade-credit relationships.

Yet a main shortcoming of Battiston et al. (2007) and more generally of the agent-based literature on financial fragility (Delli Gatti et al., 2005, and further references) is that it abstracts away from the price formation process. Indeed, in these models the dynamics of prices is determined by random process and lacks behavioral foundations. More broadly, the link between this class of agent-based models and the general equilibrium literature has, up to now, remained obscure. Clarifying the issue a second contribution of this paper. By embedding a financial fragility model à la Delli Gatti et al. in a general equilibrium framework, we show that large exogenous shocks and violations of budgetary balance conditions are not necessary to trigger a network-based financial accelerator. In our model, losses and bankruptcies are brought about by disequilibrium rather than by randomness. Hence our approach is, perhaps in a metaphorical sense, more Schumpeterian: it is out-of-equilibrium that financial fragility and bankruptcy materialize.

We use computational methods. We implement our model numerically and analyze its properties via Monte-Carlo simulations. This is the standard approach in agent-based computational economics (see LeBaron and Tesfatsion, 2008). Yet, an important innovation of our model is its hybrid nature. Part of the dynamics are defined by behavioral rules and local interactions as is standard in the agent-based literature, part are defined in a more axiomatic mode by assuming some form of efficiency, and then implemented as solutions to linear programs. This allows to reduce the number of free parameters by abstracting away from the details of processes whose time-scale or magnitude is below these of concern in the model (this perspective on time-scales is akin to the one leading to subscale parametrization in climate modeling (see Edwards, 2010)). However, this approach involves solving large and complex optimization problems on networks. Therefore it raises, for the first time as far as we know, the issue of computational capacity in the field of agent-based computational economics. The simulations presented in this paper altogether required months of computation time ${ }^{1}$ although none of them involve a large number of sectors or of firms .

The remaining of the paper is organized as follows. Section two describes

\footnotetext{
${ }^{1}$ For a single-core machine.
} 
the model. In section three, we investigate the interplay between equilibrium, financial fragility and disequilibrium. Section four analyzes the relationship between the structure of the production network, convergence to equilibrium and aggregate volatility. Section five concludes.

\section{$2 \quad$ A multisectoral model}

\subsection{The general equilibrium framework}

We investigate the dynamics of a multi-sectoral economy built up by a large number of households, firms and banks, interconnected via input-output, commercial credit, and financial credit networks.

We represent firms as financially constrained and boundedly rational agents, which combine intermediary inputs and labor in view of production, and adaptively search for a profit-maximizing pricing policy. Households are inelastic labor suppliers and can also act as entrepreneurs. Their wages and entrepreneurial profits are the only source of final demand (i.e consumption). Banks are rulebased suppliers of short-term credit.

Intermediary consumption is financed by commercial credits and hence defines two networks linking firms: one of physical/commodity flows, one of financial obligations. Wages are anticipated so that leveraged firms possibly require credit from the banks in order to finance production. These liabilities of firms towards banks define a third, financial, network linking firms and banks.

Our representation of the firm is built upon two fundamental features: firms are equity constrained (see Greenwald and Stiglitz, 1993) and adaptive price setters (see Gintis, 2007). As demonstrated in the recent literature on financial fragility (e.g Battiston et al., 2007; Delli Gatti et al., 2010), accounting for imperfect markets and financial constraints is key to understand the genesis of the financial network and the spreading of shocks in the economy through bankruptcy cascades and, more generally, financial accelerator mechanisms. Recognizing the adaptive nature of decision making and the decentralized nature of prices allows to develop micro-founded approaches of out-of-equilibrium dynamics (see Gintis and Mandel, 2012). Combining both insights allows to situate the literature on economic fragility vis-à-vis the standard general equilibrium framework and in particular to demonstrate that the propagation of shocks and volatility are essentially out-of-equilibria phenomena.

In order to perform this comparison, we root our model in a standard CobbDouglas technological infrastructure, identical to this in which Long and Plosser (1983) develop their real business cycle model and Acemoglu et al. (2012) perform their equilibrium analysis of the decay of shocks in production networks. Namely, firms are grouped in $N$ distinct sectors producing homogeneous goods. The production possibilities of firms in sector $g$ are described by a production 
function $F_{g}: \mathbb{R}_{+}^{N+1} \rightarrow \mathbb{R}_{+}$, such that:

$$
F_{g}\left(l_{g}, x_{g}\right)=\gamma_{g} l_{g}^{\alpha_{g}} \prod_{h=1}^{N} x_{g, h}^{\left(1-\alpha_{g}\right) \omega_{g, h}}
$$

where the parameters $\left.\gamma_{g}>0, \alpha_{g} \in\right] 0,1\left[\right.$ and $\omega_{g, h} \geq 0$ such that $\sum_{h=1}^{N} \omega_{g, h}=1$ respectively represent productivity, the share of labor and the share of good $h$ in the total intermediate input use of firms in sector $g$, while the variables $l_{g}$ and $x_{g, h}$ respectively correspond to the amount of labor hired and the amount of commodity $h$ used in the production process. The coefficient $\omega_{g, h}$ can be related to the entry of an input-output table measuring the value of spending on input $h$ per dollar of production of good $g$.

Each household inelastically supplies a unit of labor. Whenever individual preferences have to be introduced, in order to ensure comparability with the equilibrium literature, we shall assume that individual are characterized by utility functions of the form

$$
u\left(c_{1}, \cdots, c_{N}\right)=\prod_{h=1}^{N} c_{h}^{v_{h}}
$$

where the variable $c_{h}$ stands for the consumption of good $g$ and the parameter $v_{h} \geq 0$ such that $\sum_{h=1}^{N} v_{h}=1$ empirically corresponds to the share of expenses devoted to good $h$.

We will consider there is the same finite number $M \in \mathbb{N}$ of households and of firms in each sector ${ }^{2}$ and denote the economy by $\mathcal{E}(M, N, \alpha, \gamma, \omega, v)$, the set of goods, by $\mathcal{G}=\{1, \cdots, N\}$, the set of firms by $\mathcal{F}=\{(g, j) \mid g \in \mathcal{G}, j \in\{1, \cdots M\}\}$ and the set of households by $\mathcal{H}=\{1, \cdots, M\}$.

We can then define the equilibrium of the economy $\mathcal{E}(M, N, \alpha, \gamma, \omega, v)$ as follows.

Definition 1 An equilibrium of the economy $\mathcal{E}(M, N, \alpha, \gamma, \omega, v)$ is any collection of prices $p^{*} \in \mathbb{R}_{+}^{N}$, labor cost $w^{*} \in \mathbb{R}_{+}$, consumption $\left(x_{i}^{*}\right)_{i=1, \cdots, M} \in \mathbb{R}_{+}^{N \times M}$ and production plans $\left(l_{g, j}^{*}, y_{g, j}^{*}\right)_{g=1, \cdots, N, j=1, \cdots, M} \in\left(\mathbb{R}_{+} \times \mathbb{R}_{+}^{N}\right)_{+}^{N \times M}$ such that:

1. For all $i=1 \cdots M$, household $i$ maximizes utility:

$$
x_{i}^{*}:=\operatorname{argmax}_{p_{i}^{*} \cdot x_{i} \leq w^{*}} u\left(x_{i}\right)
$$

2. For all $g=1 \cdots N, j=1 \cdots M$, firm $(g, j)$ maximizes profit:

$$
y_{g, j}^{*}:=\operatorname{argmax}_{F_{g}\left(l_{g, j}, y_{g, j,-g}\right)=y_{g, j, g}} p_{g}^{*} \cdot y_{g, j, g}-p_{-g}^{*} \cdot y_{g, j,-g}-w^{*} l_{g, j}
$$

\footnotetext{
${ }^{2}$ The number of firms per sector and of households is set identically to simplify the exposition and the normalization of variables.
} 
3. Good markets clear:

$$
\sum_{g=1}^{M} \sum_{j=1}^{N} y_{g, j}^{*}=\sum_{i=1}^{M} x_{i}^{*}
$$

4. Labor market clears:

$$
\sum_{g=1}^{M} \sum_{j=1}^{N} l_{g, j}^{*}=M
$$

Once labor is defined as the numéraire and has its price fixed ${ }^{3}$ it is straightforward to show that the equilibrium of this economy is unique up to the allocation of production among firms. In particular there is a unique equilibrium price for goods, $p^{*} \in \mathbb{R}_{+}^{N}$ such that ${ }^{4}$ :

$$
\log \left(p^{*}\right)=(I d-\omega)^{-1}\left(\begin{array}{c}
-\log \left(\gamma_{1}\right)-\alpha_{1} \log \left(\alpha_{1}\right)-\sum_{h=1}^{N} \log \left(\omega_{1, h}\right) \\
\ldots \\
-\log \left(\gamma_{1}\right)-\alpha_{1} \log \left(\alpha_{1}\right)-\sum_{h=1}^{N} \log \left(\omega_{N, h}\right)
\end{array}\right)
$$

\subsection{The State Space}

In order to extend the static results of Acemoglu et al. (2012) on the decay of aggregate volatility and to clarify the relationships between the agent-based financial fragility literature (see Battiston et al., 2007; Delli Gatti et al., 2010) and general equilibrium, we undertake an exploration of out-of-equilibrium dynamics in the economy $\mathcal{E}(M, N, \alpha, \gamma, \omega, v)$.

In order to accurately account for financial interactions, we shall introduce $M$ financial agents or banks whose set is denoted by $\mathcal{B}$. Bank $k$ will be characterized throughout by a level of net worth $a_{k}$, corresponding to its financial capital .

Two key state variables will govern the behavior of firms and households: a vector of private prices and a level of net worth. More precisely, we will denote by $p_{g, j} \in \mathbb{R}_{+}^{N}$ and $a_{g, j} \in \mathbb{R}_{+}\left(\operatorname{resp} p_{i} \in \mathbb{R}_{+}^{N}\right.$ and $\left.a_{i} \in \mathbb{R}_{+}\right)$the vector of private prices and the net worth of the $j$ th firm $^{5}$ in sector $g$ (resp. of the $i$ th household) and let $(p, a) \in P \times A:=\left(\mathbb{R}_{+}^{N}\right)^{(N+1) M} \times\left(\mathbb{R}^{+}\right)^{(N+2) M}$ denote the complete state of the system (it also includes the net worths of banks).

The private price for good $h$ of firm $(g, j)$ (resp. of the $i$ th household), $p_{g, j, h}$ (resp. $p_{i, h}$ ), is a reserve price, the maximum price the firm (resp. the household) is willing to pay for that good. The private price of firm $(g, j)$ for its own good, $p_{g, j, g}$, is the price at which it is offering its output for sale. On top of being an accurate representation of the fact that firms actually are price setters, private prices have good asymptotic properties in terms of convergence

\footnotetext{
${ }^{3}$ In the following, we set the labor cost in such a way that the mean price of commodities equals one at equilibrium

${ }^{4}$ We denote by $I d$ the identity matrix of size $n$. A detailed derivation is given in the appendix of Acemoglu et al. (2012).

${ }^{5}$ Firm $(g, j)$ hereafter.
} 
to general equilibrium when updated according to evolutionary dynamics, see Gintis and Mandel (2012).

The net worths of households correspond to cash holdings to be spent on consumption. The net worth of firm $(g, j), a_{g, j}$, represents the amount of financial capital it can autonomously employ in the production process. In line with the idea of having credit-constrained firms à la Greenwald and Stiglitz (1993), we use financial capital as a measure of the firm's financial robustness and determine accordingly the extent of a firm's access to credit and hence its production capacity. Namely, we shall assume following previous work by Delli Gatti et al., that the production capacity of firm $(g, j)$ is given by the financially constrained output function:

$$
f\left(a_{g, j}\right)=\phi a_{g, j}^{\beta}
$$

where $a_{g, j} \in \mathbb{R}_{+}$is the net worth the firm holds, $\phi>0$, and $0<\beta<1$. The parameters $\phi$ and $\beta$ condition the intensity at which capital is put in motion in the economy. More precisely, $\beta$ measures the extent to which there are "decreasing returns" to financial robustness in terms of credit leverage, and eventually production, it can yield. These parameters also implicitly define the time-scale of the model through the production to capital ratio.

The initial stock of money in the model consists in the sum of the net worths of banks, firms and households. Permanent addition to the stock of money can occur at runtime in case a bank goes bankrupt (see below).

\subsection{Initialization and transition}

Initialization of the model consists in the choice of an initial value for the net worth and private prices of each agent, i.e of an element $\left(p^{0}, a^{0}\right) \in P \times A:=$ $\left(\mathbb{R}_{+}^{N}\right)^{(N+1) M} \times\left(\mathbb{R}^{+}\right)^{(N+2) M}$. Then, every period the following operations take place sequentially:

- Real Step. The quantities of goods produced, exchanged and consumed are determined as a function of net worths and private prices.

- Financial Step. The evolution of agents' net worths are determined, on the one hand by the outcome of the production and exchange processes and on the other hand by the inflows and outflows of money between the productive and the financial sector induced by the credit scheme according to which production is financed. At this stage, firms and banks can go bankrupt if their net worth becomes negative. New firms and banks are then funded from existing capital in the financial sector.

- Price Step. The evolution of agents' private prices is determined according to stochastic evolutionary dynamics that use as measures of fitness the profit of firms and the utility of households.

A time step of the model hence consists in the sequential application of the real, financial and price steps. It returns updated values on one hand for the net 
worth and private prices of each agent and on the other hand for the economic variables (production, consumption, profits,...) that have been correlatively determined. Our actual assumptions about economic dynamics are embedded within the description of each of these steps that is given below.

\subsection{Real Dynamics}

In order to capture the dynamic interactions between prices, quantities, and credit conditions, we must first specify how a private price and net worth profile $(p, a) \in P \times A$ determines the level of production and its allocation in the economy. In agent-based models, (e.g Dosi et al., 2010; Dawid et al., 2012; Wolf et al., 2013; Mandel, 2012), this process is generally emerging from a very detailed representation of the firms' decisions and of their interactions on the different markets. We consider that our analysis can abstract away from part of these details as the time-scale at which they matter is below this that is of concern when one focuses on aggregate volatility and convergence to equilibrium. This perspective on time-scales is akin to the one leading to subscale parametrization in climate modeling (see Edwards, 2010).

We shall also consider as a first approximation that production and allocation of goods take place in a frictionless ${ }^{6}$ way given the constraints implied by the compatibility of private prices and the financial capacity. Finally, we shall assume the agents are "computationally" rational in the sense that they are able to perform cost minimization operations. These assumptions yield the following representation of the production and allocation processes.

Firms determine a cost efficient input mix as follows. On the one hand, they evaluate the costs of commodity inputs on the basis of their private prices. On the other hand, they assign to the labor input, wages to be paid at the rate $w$ (which is fixed throughout the paper) as well as a mark-up $v \in[0,1]$ that ought to generate a surplus for the owner/entrepreneur of the firm in case the production is actually profitable (see subsection 2.5 .3 below). Hence, firm $(g, j)$ chooses an input combination proportional to

$$
\left(\mu_{g, j}, \nu_{g, j}\right):=\operatorname{argmin}_{F_{g}\left(l_{g}, x_{g}\right)=1} p_{g, j} x_{g}+(1+v) w l_{g}
$$

and therefore uses $\mu_{g, j}$ units of labor and a vector $\nu_{g, j}$ of commodities per unit of output produced.

Remark 1 Note that the mark-up rate $v$ also determines the repartition of the value-added that shall prevail at equilibrium: a share $\lambda:=\frac{1}{1+v}$ should be allocated to workers and a share $1-\lambda:=\frac{v}{1+v}$ to the owner/entrepreneur of the firm.

\footnotetext{
${ }^{6}$ It would be straightforward to introduce frictions in the process, e.g by considering that a certain share of production dissipates instead of being consumed. It seems reasonable to focus first on the frictionless case and to delay generalization to further work.
} 
Households choose their preferred consumption mix given their private prices. That is household $i$ consumes proportionally to

$$
\gamma_{i}:=\operatorname{argmax}_{p_{i} \cdot x_{i} \leq 1} u_{i}\left(x_{i}\right) .
$$

In other words, household $i$ will consume $\gamma_{i, h}$ units of good $h$ for every unit of income spent.

Let us then denote by $z_{(g, j),\left(g^{\prime}, j^{\prime}\right)}$ the flow of good $g$ from firm $(g, j)$ to firm $\left(g^{\prime}, j^{\prime}\right), z_{(g, j), i}$ the flow of good $g$ from firm $(g, j)$ to household $i, z_{i,(g, j)}$ the flow of labor from household $i$ to firm $(g, j), l_{g, j}$ the quantity of labor employed by firm $(g, j), x_{g, j, g^{\prime}}$ the quantity of good $g^{\prime}$ used as input by firm $(g, j), x_{i, g^{\prime}}$ the quantity of good $g^{\prime}$ consumed by household $i, y_{g, j}$ the quantity of output produced by firm $(g, j)$ and $w_{i}$ the income of household $i$. The production and the allocation of goods are then determined as a solution of the following maximization problem.

$$
\left\{\begin{array}{cc}
\max & \min _{g \in \mathcal{G}} \frac{\sum_{i=1}^{M} x_{i, g}}{\sum_{i=1}^{M} \gamma_{i, g}} \\
\text { s.t } & \forall(g, j),\left(g^{\prime}, j^{\prime}\right) \in \mathcal{F}, z_{(g, j),\left(g^{\prime}, j^{\prime}\right)}>0 \Rightarrow p_{g, j, g} \leq p_{g^{\prime}, j^{\prime}, g} \\
(i) & \forall(g, j), \in \mathcal{F}, \forall i \in \mathcal{H} z_{(g, j), i}>0 \Rightarrow p_{g, j, g} \leq p_{i, g} \\
(i i) & \forall(g, j) \in \mathcal{F}, l_{g, j}=\sum_{i \in \mathcal{H}} z_{i,(g, j)} \\
(\text { iii }) & \forall(g, j) \in \mathcal{F}, \forall g^{\prime} \in \mathcal{G} x_{g, j, g^{\prime}}=\sum_{\left\{j^{\prime} \mid\left(g^{\prime}, j^{\prime}\right) \in \mathcal{F}\right\}} z_{\left(g^{\prime}, j^{\prime}\right),(g, j)} \\
(i v) & \forall(i) \in \mathcal{H}, \forall g \in \mathcal{G} x_{i, g}=\sum_{\{j \mid(g, j) \in \mathcal{F}\}} z_{(g, j), i} \\
(v) & \sum_{\left\{\left(g^{\prime}, j^{\prime}\right) \in \mathcal{F}\right\}} z_{(g, j),\left(g^{\prime}, j^{\prime}\right)}+\sum_{\{i \in \mathcal{H}\}} z_{(g, j), i} \leq y_{g, j} \\
(v i) & \forall(g, j) \in \mathcal{F}, j(g, j) \in \mathcal{F}, \mu_{g, j}, y_{g, j} \leq l_{g, j} \\
\text { (vii) } & \forall(g, j) \in \mathcal{F}, \forall g^{\prime} \in \mathcal{G}, \nu_{g, j, g^{\prime}} y_{g, j} \leq x_{g, j, g^{\prime}} \\
(\text { viii }) & \forall(g, j) \in \mathcal{F}, y_{g, j} \leq f\left(a_{g, j}\right) \\
(i x) & \forall i \in \mathcal{H}, w_{i}=w \sum_{\{(g, j) \in \mathcal{F}\}} z_{i,(g, j)} \\
(x) & \forall i \in \mathcal{H}, \forall g \in \mathcal{G}, x_{i, g} \leq\left(w_{i}+a_{i}\right) \gamma_{i, g} \\
(x i) &
\end{array}\right.
$$

This amounts to assume that the production and allocation processes are efficient in the sense that as large a share of demand as possible is fulfilled. More precisely, the minimal ratio of consumption to demand among goods $\left(\min _{g \in \mathcal{G}} \sum_{i=1}^{M} x_{i, g} / \sum_{i=1}^{M} \gamma_{i, g}\right)$ is maximized. Still, behavioral, technological and institutional constraints apply.

Conditions $(i)$ and $(i i)$ state that agents only trade with peers using compatible prices. Namely there can be a flow of good $g$ between firm $(g, j)$ and firm $\left(g^{\prime}, j^{\prime}\right)$ (resp. household $i$ ) only if the private price of firm $\left(g^{\prime}, j^{\prime}\right)$ for good $g$ (i.e its reserve price) is lower than the private price of firm $(g, j)$ for its own good (i.e its selling price). Note that this is the least demanding assumption that is consistent with the presence of private prices. In other words, it allows for the largest number of trade opportunities to be seized. Yet the objective function, which is to maximize satisfaction of demand, will direct trade prioritarily towards the agents with the lowest selling price. 
Conditions $(i i i)$ to $(v)$ states that quantities are conserved during trades: (iii) expresses the fact that the labor input of firm $(g, j), l_{g, j}$, is equal to the outflow of labor from its employees while $(i v)$ states that its input in good $g^{\prime}$, $x_{g, j, g^{\prime}}$, is equal to the outflow of good from its suppliers. Condition $(v)$ is a similar condition for the consumption inputs of household $i$.

Conditions (vi) to $(i x)$ express the constraints on production. Namely, (vi) states that the outflow of good from firm $(g, j)$ must be less than its production In other words, we assume that goods can't be stored as inventories. Condition (vii) and (viii) are technological constraints. They assert, in accordance with equation (4), that firm $(g, j)$ uses $\mu_{g, j}$ units of labor and a vector $\nu_{g, j}$ of commodities per unit of output produced. Finally, condition $(i x)$ is the financial constraint on production given by equation (3).

Conditions $(x)$ and $(x i)$ are constraints on the household's income and budget. Condition $(x)$ computes the household's labor income under the assumption that labor supply is uniformly paid at the unit wage $w$. Condition $(x i)$ states, first that the total budget to be spent on consumption is equal to this period's labor income plus wealth transferred from the preceding period (the latter accounts mainly for dividends received last period, see subsection 2.5.3) and second that, in accordance with equation (5), household $i$ spends a share $\gamma_{i, g}$ of its budget on good $g$.

Hence production, income and consumption are completely determined by the profile of private prices and net worth $(p, a) \in P \times A$. These being given, the economy functions in an "efficient" way in the sense that as large a share as possible of the final demand is fulfilled given the financial and price compatibility constraints. However, there are two potentially major sources of inefficiency related respectively the distribution of financial capital and of prices. Concerning financial capital, it might be misallocated, what leads to capacity shortage and rationing in certain sectors and to capacity underutilization in others. Concerning prices they might be dispersed, hence preventing trading, or they might be away from their equilibrium values, what leads to rationing, misallocation of goods, abnormal profits and losses and eventually bankruptcies. Note in particular that unless agents all use the same equilibrium price, supply and demand can't balance exactly and hence constraints (vi) and (viii) can't bind simultaneously: there must be excess supply or inefficient use of inputs. Both can trigger losses. Conversely, there might be abnormal profits in sectors with excess demand.

Though it is standard in economic theory to focus on equilibrium situations only, it is necessary here to introduce explicitly out-of-equilibrium trading as we focus on the (possible) emergence of equilibrium (see Fisher, 1989). In this context, to have firms act a price-makers is consistent with the fact that prices are set in a decentralized manner in market economies and also consonant with Walras' (1874) original description of the workings of competition in decentralized markets: out-of-equilibrium, price-setting firms strategically raise or lower their prices in order to adapt to market conditions. Note however that firms are effectively price-makers only when markets are in disequilibrium. As we shall see below, they can remain so if competition is indeed imperfect (e.g because 
of interferences with financial constraints). On the contrary, if competition is strong enough, an equilibrium regime is established in which unilateral price deviation are unprofitable so that the law of one price and price-taking behavior appear as emergent properties of the model (see below).

\subsection{Financial Dynamics}

\subsubsection{Credits and Interests}

The financial counterparts of the production and exchange processes are determined by the magnitude of these exchanges as well as by the scheme according to which they are financed. We shall consider here a setting à la Delli Gatti et al. (2010), which account both for commercial credit between firms and financial credit extended to firms by banks. Namely, we shall assume that sales of productive inputs are financed by a commercial credit extended by the seller to the buyer while wages are anticipated (i.e paid cash by the firms) and the excess of the wage bill over the net worth of the firm is financed by a credit extended by its bank to the firm (For each $g \in \mathcal{G}$, firm $(g, j)$ is initially linked to bank $j$; the dynamics of the financial network are specified in subsection 2.6.1).

Following Delli Gatti et al. (2010), we consider the interest rates on both commercial and financial credit are decreasing with the financial soundness (i.e the net worth) of the lender and increasing with the leverage (i.e the ratio between the level of debt and the net worth) of the borrower. More precisely the interest rate charged by lender $\ell$ (be it a bank or a firm ) to borrower $b$ is:

$$
r_{\ell, b}=\rho \underline{a}_{\ell}^{-\rho}+\rho\left(\frac{\underline{d}_{b}}{\underline{a}_{b}}\right)^{\rho}
$$

where $\underline{a}_{b}$ (resp. $\underline{a}_{l}$ ) refers to the net worth of the borrower (resp. of the lender) at the beginning of the period, $\underline{d}_{b} \in \mathbb{R}_{+}$is the total debt of the borrower before interest (i.e the sum of the principals of the firm's debts towards firms and banks given below) and the parameter $\rho \in \mathbb{R}_{+}$controls the sensitivity of the interest rate (see Delli Gatti et al., 2010, for details). Note that through the dependence of the interest rate on the lender's financial soundness, the credit network plays a central role in the transmission and the amplification of financial shocks. Indeed, as further described in section 3.3, the bankruptcy of a borrower then affects not only the lender's balance sheet but also indirectly all the other borrowers to which the lender is connected because of the resulting increase in the interest rate charged by the lender.

\subsubsection{Clearing}

After production and allocation operations have taken place, the financial status of a firm $(g, j)$ is given by:

- Its net worth which consists on the one hand of the cash payments it received from households during the period and on the other hand of 
the net worth it had at the beginning of the period net of the wage bill (conversely, if the wage bill was greater than the available net worth, the corresponding part of the net worth is zero and the difference is part of the firm's debt). More precisely, the updated net worth of firm $g, j$ is given by $^{7}$ :

$$
a_{g, j}=\sum_{i \in \mathcal{H}} p_{g, j, g} z_{(g, j), i}+\max \left(0, \underline{a}_{g, j}-w l_{g, j}\right)
$$

- Its liabilities towards other firms, which consist in the commercial credit it has been granted plus interest payments. That is the debt of firm $(g, j)$ towards firm $\left(g^{\prime}, j^{\prime}\right)$ is given by:

$$
d_{(g, j),\left(g^{\prime}, j^{\prime}\right)}:=\left(1+r_{\left(g^{\prime}, j^{\prime}\right),(g, j)}\right) \underline{d}_{(g, j),\left(g^{\prime}, j^{\prime}\right)}
$$

where the principal of the debt is given by

$$
\underline{d}_{(g, j),\left(g^{\prime}, j^{\prime}\right)}:=p_{g^{\prime}, j^{\prime}, g^{\prime}} z_{\left(g^{\prime}, j^{\prime}\right),(g, j)}
$$

- Its liabilities towards its bank, which consist in the credit it has been granted to finance its wage bill plus the interest payments. Namely, the debt of firm $(g, j)$ towards its bank $k$ is given by:

$$
d_{(g, j), k}:=\left(1+r_{k,(g, j)}\right) \underline{d}_{(g, j), k}
$$

where the principal of the debt is given by

$$
\underline{d}_{(g, j), k}=\min \left(0, w l_{g, j}-\underline{a}_{g, j}\right)
$$

Debts are then cleared by compensation. If complete clearing is impossible because of default, that is if there are firms for which the value of liabilities exceeds the one of assets (net worth plus debts from other firms), defaulting firms are bankrupted/liquidated and their assets shared uniformly among creditors. More precisely, the following clearing algorithm is implemented.

1. If for all $(g, j) \in \mathcal{F}$, one has:

$$
a_{g, j}+\sum_{\left\{\left(g^{\prime}, j^{\prime}\right) \in \mathcal{F}\right\}} d_{\left(g^{\prime}, j^{\prime}\right),(g, j)} \geq \sum_{\left\{\left(g^{\prime}, j^{\prime}\right) \in \mathcal{F}\right\}} d_{(g, j),\left(g^{\prime}, j^{\prime}\right)}+\sum_{\{k \in \mathcal{B}\}} d_{(g, j), k}
$$

then all the debts can be cleared by having each firm $(g, j)$ adding to its financial capital $a_{g, j}$ a net transfer of

$$
\sum_{\left\{\left(g^{\prime}, j^{\prime}\right) \in \mathcal{F}\right\}} d_{\left(g^{\prime}, j^{\prime}\right),(g, j)}-\sum_{\left\{\left(g^{\prime}, j^{\prime}\right) \in \mathcal{F}\right\}} d_{(g, j),\left(g^{\prime}, j^{\prime}\right)}-\sum_{\{k \in \mathcal{B}\}} d_{(g, j), k}
$$

and each bank $k$ adding to its financial capital $a_{k}$ a net transfer of

$$
\sum_{\left\{\left(g^{\prime}, j^{\prime}\right) \in \mathcal{F}\right\}} d_{\left(g^{\prime}, j^{\prime}\right), k}-\sum_{\left\{\left(g^{\prime}, j^{\prime}\right) \in \mathcal{F}\right\}} \underline{d}_{\left(g^{\prime}, j^{\prime}\right), k} .
$$

\footnotetext{
${ }^{7}$ Recall that $a$ refers to the net worth at the beginning of the period
} 
2. Otherwise, each firm $\left(g_{0}, j_{0}\right) \in \mathcal{F}$ such that the condition 1 . above does not hold goes bankrupt. Its assets are allocated to its creditors proportionally to the amount of outstanding debt. That is, the net worth and the claims of each firm and bank are updated as follows (the symbol $+=$ denotes an incrementation, that is the variable on the left-hand side is updated by adding the value of the expression on the right-hand side):

For all $\ell \in \mathcal{F} \cup \mathcal{B} /\left\{\left(g_{0}, j_{0}\right)\right\}$ :

$$
\left\{\begin{array}{l}
a_{\ell}+=\frac{d_{\left(g_{0}, j_{0}\right), \ell}}{\sum_{\left\{\left(g^{\prime}, j^{\prime}\right) \in \mathcal{F}\right\}} d_{\left(g_{0}, j_{0}\right),\left(g^{\prime}, j^{\prime}\right)}+\sum_{\{k \in \mathcal{B}\}} d_{\left.\left(g_{0}, j_{0}\right), k\right)}} a_{g_{0}, j_{0}} \\
\forall\left(g^{\prime}, j^{\prime}\right) \in \mathcal{F}, \\
d_{\left(g^{\prime}, j^{\prime}\right), \ell}+=\frac{d_{\left(g_{0}, j_{0}\right), \ell}}{\sum_{\left\{\left(g^{\prime}, j^{\prime}\right) \in \mathcal{F}\right\}} d_{\left(g_{0}, j_{0}\right),\left(g^{\prime}, j^{\prime}\right)}+\sum_{\{k \in \mathcal{B}\}} d_{\left.\left(g_{0}, j_{0}\right), k\right)}} d_{\left(g^{\prime}, j^{\prime}\right),\left(g_{0}, j_{0}\right)}
\end{array}\right.
$$

For $\left(g_{0}, j_{0}\right)$ :

$$
\left\{\begin{array}{l}
a_{\left(g_{0}, j_{0}\right)}:=0 \\
\forall\left(g^{\prime}, j^{\prime}\right) \in \mathcal{F}, \\
d_{\left(g^{\prime}, j^{\prime}\right),\left(g_{0}, j_{0}\right)}:=0
\end{array}\right.
$$

3. 1. and 2. are repeated until all firms are sound in the sense of 1 .

It is relatively easy to check that this algorithm stops after a finite number of iterations as there is at least one bankruptcy per (non-terminal) iteration and at most $N \times M$ firms can go bankrupt. Note also that each creditor is treated in a purely symmetric manner but possibly for the order according to which bankrupted firms are litigated, and this latter point does not affect the outcome of the algorithm (see Eisenberg and Noe, 2001).

A key implication of the presence of commercial credit in the model and of the clearing mechanism is that the actual/financial profit of the firm does not only depend on its commercial performance, which it can "control" through its pricing policy, but also on the financial soundness of its partners, through which it is in fact exposed to the whole credit network. Indeed the debt clearing mechanism can propagate default far away from its source. The firm is hence exposed to a systemic risk whose manifestations appear as random (at least from the firm's point of view). The only influence the firm has on this risk is through the interest rate it charges. However, because of systemic effects, the idea of mitigating risk by a higher interest rate might be self-deceiving (see Battiston et al., 2012a).

\subsubsection{Accounting and financial flows}

Actual/financial profits of firms are computed as the net increase in wealth after the clearing of debts. Profits might differ from the value of sales minus production costs because some of the firm's creditors might have gone bankrupt 
and default on their commercial debt. Part of these profits are retained by the firm in order to increase its financial capital, part are distributed to the household sector. More precisely, for each $g=1 \cdots N$ and each $j=1 \cdots M$, firm $(g, j)$ distributes to household $j$ a dividend equal to the minimum between its financial profit and the entrepreneurial share $1-\lambda$ in the value-added. More precisely, if the financial profit is negative no dividend is distributed and if it is positive, the dividend is set equal to:

$$
\min \left(a_{g, j}-\underline{a}_{g, j},(1-\lambda)\left(p_{g, j} y_{g, j}-\sum_{h=1}^{N} \sum_{k=1}^{M} p_{h, k} z_{(h, k),(g, j)}\right)\right) .
$$

The remaining share of the profit is retained in the firm's capital. As far as the banks are concerned they retain all their profits.

As far as losses are concerned, they are covered by the financial capital of the agents (see clearing algorithm above) until the losses excess the financial capital available, in which case the corresponding agent goes bankrupt. The bankrupted firms are determined during the clearing algorithm. The amount of their outstanding debts correspond to losses which are shared among their creditors. The bankrupted banks are those whose financial capital becomes negative after the clearing algorithm, that is banks $k$ such that $a_{k}<0$. Note that the outstanding deficit of a bankrupted bank does not have a counterpart in the model. Indeed, this counterpart shall consist in debts to other banks which credited their customers with (wage) payments made out of the money lent by the bankrupted bank. However, as we do not represent interbank clearing, these debts are not explicit and the loss can't be assigned. As a consequence, the stock of money increases of the corresponding amount ${ }^{8}$.

Each bankrupted firm and bank is then replaced by a new entrant that is capitalized as follows.

- For each new firm, a bank is drawn at random to capitalize it. The new capital of the firm is set equal to to the minimum between half the bank's capital and the mean wealth of firms in the economy. The corresponding amount is subtracted from the capital of the bank that finances the capitalization.

- For each new bank, another bank is drawn at random to capitalize it. The outstanding deficit is foregone and the target new capital of the bank is set equal to the mean capital of banks in the economy. However, as for the firms, the actual capitalization can not exceed half the capital of the bank financing the operation.

These assumptions correspond to an institutional setting in which firms are managed by entrepreneurial households and funded by banks. The managers

\footnotetext{
${ }^{8}$ In fact, everything goes as if the functioning of the payment system was guaranteed by the central bank through a commitment to compensate, via money creation, defaults in the interbank clearing system.
} 
capture part of the profit (the part that is distributed), the other part consists in retained earnings that increase the firm's capital and therefore allows the firm to expand. The assumption that each household manages the same number of firms (he receives compensation from all firms whose index is the same as his, see above) is certainly over-simplistic but the distribution of wealth among households has little impact on the dynamics of our model given that consumption behavior is independent of the level of income (see subsection 2.4). The assumption that firms are funded by banks rather than by households is consistent with the fact that there are neither motives nor means for savings in a setting where there is no capital accumulation and the only financial assets are intra-period loans. As a matter of fact, in absence of capital accumulation, aggregate budgetary balance implies that all income should be spent on consumption.

The bankruptcy rules for firms are such that the stock of money is conserved and hence the model is stock-flow consistent with the caveat that whenever a bank goes bankrupt, the amount of its outstanding deficit yields a net monetary creation of the same amount. The aggregate flows of capital between the productive and the financial sectors are determined by the level of debt and interests and by the financial fragility of the system. On the one hand, interests payments induce a transfer of capital from the productive to the financial sector. On the other hand, default and recapitalization of firms following bankruptcies induce a transfer from the financial to the productive sector. Different feedback mechanisms are also at play. A negative one following which a net transfer from the productive to the financial sector increases the capital basis in the financial sector and hence pushes downwards the interest rate. A positive one following which a net transfer from the productive to the financial sector increases financial fragility in the productive sector and hence pushes upwards the interest rate.

We investigate in details the outcome of these interconnected processes in section 3. The key issue is the speed and the magnitude at which the financial system can exchange capital with the productive sectors. It turns out that this will be mainly determined by the total capital in the financial sector and the distribution of wealth in the productive sector ${ }^{9}$.

\subsection{Price Dynamics}

Our representation of prices dynamics is in line with the core assumptions in general equilibrium theory that firms are profit maximizers and households are utility maximizers. Yet, we consider that this optimization is taking place adaptively through stochastic evolutionary process in which firms update their com-

\footnotetext{
${ }^{9}$ Yet it shall be emphasized that in many respects, our representation of the financial system is over-simplistic. In particular, the capital of banks is here more of a buffer than a truly operative variable. For example, leverage of banks is unbounded in our setting (banks' capital only affects the interest rate) and the only rationale for banks to invest in firms are capital gains (they never receive dividends) although we lack the representation of the market for firms' stocks.
} 
petitiveness and their profitability through their private prices and households update their consumption plan through a monetary evaluation again based on their private prices. It turns out that this approach has much better dynamical properties than the Walrasian tâtonnement (see Gintis and Mandel, 2012).

Stochastic evolutionary processes are based on a measure of fitness that determines which strategies are imitated and which disappear. In our case, the fitness of an household is computed during consumption operations as the ratio between utility and income. The fitness of a firm is the ratio of profit to net worth at the beginning of the period (i.e return on equity). Agents are then pooled according to their types: all households together and producers by sectors. There are $N+1$ such pools, each consisting of $m=1 \cdots M$ agents characterized by a fitness $f_{m}$ and a private price $p_{m}$. Prices are updated independently for each pool of agents according to the following algorithm (from Gintis, 2007).

1. Normalized fitness $\bar{f}_{m}$ are computed according to $\bar{f}_{m}=\frac{f_{m}-f_{\min }}{f_{\max }-f_{\min }}$.

2. Until a fraction $\tau_{\text {copy }}$ of agents have been selected as imitators, an agent is drawn at random and selected as an imitator with probability $1-\bar{f}_{m}$. Similarly, until a fraction $\tau_{\text {copy }}$ of agents have been selected as models, an agent is drawn at random and selected as a model with probability $\bar{f}_{m}$.

3. Each imitator is randomly paired with a model and copies its private price. That is the imitator $m$, if paired with the model $m^{\prime}$, sets the value of its private price to $p_{m^{\prime}}$.

Then prices mutate (see again Gintis, 2007), that is $\tau_{\text {mutate }}$ agents are randomly drawn and independently for each good divide or multiply (each with probability one half) their price by a factor $\mu$. That is if $p_{k, g}$ is the private price of good $g$ for agent $k$ before mutation, the mutation turns it to $\mu p_{k, g}$ with probability $1 / 2$ and to $p_{k, g} / \mu$ with probability $1 / 2$. Eventually, each firm checks the consistency of its prices by ensuring its selling price is at least equal to its unit production cost.

Mutations might account for errors in the imitation process or random innovation. Their structural importance comes from the fact that they make the evolutionary process ergodic.

\subsubsection{Dynamics of the financial network}

For each $g \in \mathcal{G}$, firm $(g, j)$ is initially linked to bank $j$. The dynamics of the financial network are identical to those in Delli Gatti et al. (2010). In every period, after accounting takes place, each firm observes the interest rates offered by a randomly selected sample of $30 \%$ of the population of banks. If the interest rate $r_{\text {old }}$ offered by the current bank is less than the minimum interest rate $r_{n e w}$ offered in the sample of banks observed, the firm sticks to its current bank. Otherwise, with probability $1-e^{\left(r_{n e w}-r_{o l d}\right) / r_{n e w}}$ the firm shifts to the bank offering the interest rate $r_{n e w}$. In other words, the lower the alternative 
interest $r_{n e w}$, the larger is the probability that the firm shifts to the competing bank.

\subsection{Simulation setting}

We investigate the dynamics of the model via numerical simulations. A period of the model corresponds to the sequential execution of the real, financial and price steps and a simulation corresponds to the iteration of the model for a finite number of periods. The model is implemented in Matlab ${ }^{10}$ and the linear program in subsection (2.4) is solved using IBM ilog cplex optimization studio ${ }^{11}$. The default parameters for simulations are reported in table 1 . Some remarks about the relation between simulation and the nature of the dynamics are also in order at this stage.

- The real step is formally non-deterministic as it involves picking-up a solution to the linear program in subsection (2.4) that can a priori admit many such solutions. Yet, our implementation is deterministic as long as the behavior of the optimization algorithms we use are. This shall be the case $^{12}$.

- The financial step is deterministic.

- The price step is stochastic but is implemented on the basis of a pseudorandom number generator in order to ensure reproducibility of results.

\section{General equilibrium and financial fragility.}

The general equilibrium of the economy $\mathcal{E}(M, N, \alpha, \gamma, \omega, v)$ will play a central role in our analysis as most of our results are stated vis-à-vis this equilibrium: convergence to equilibrium, mean residence time in or away of equilibrium, effects of the structure of the production network or of financial constraints on equilibrium. It is therefore fundamental to characterize equilibrium in our model: both analytically and as a reference point of the dynamics of simulations.

\subsection{Financial viability and Equilibrium}

In the economy $\mathcal{E}(M, N, \alpha, \gamma, \omega, v)$, the equilibrium consumption of each household and the equilibrium production aggregated at the sectoral level can be inferred from the equilibrium price (see definition 1 and equation 2). However, as there are constant returns to scale, profit maximization yields zero profits.

\footnotetext{
${ }^{10}$ MATLAB and Statistical Toolboxes Release 2013b, The MathWorks, Inc., Natick, Massachusetts, United States.

${ }^{11}$ Made freely available for academic use by IBM. This IBM academic initiative is gratefully acknowledged.

${ }^{12}$ According to the software provider: see CPLEX user's manual on Advanced programming techniques/Parallel optimizers/Determinism of results
} 


\begin{tabular}{|c|c|c|}
\hline Symbol & Interpretation & Default value \\
\hline$N$ & sectors & 3 \\
\hline$M$ & agents per sector & 50 \\
\hline$\gamma$ & productivity parameter & 0.5 \\
\hline$\alpha$ & share of labor in production & $\forall g, g^{\prime} \in \mathcal{G}, \omega_{g, g^{\prime}}=\frac{1}{N}$ \\
\hline$\omega$ & input-output table & $\forall g, \in \mathcal{G}, v_{g},=\frac{1}{N}$ \\
\hline$v$ & expenditure shares & 0.95 \\
\hline$\lambda$ & share of labor in value-added & 0.9 \\
\hline$\phi$ & magnitude of leverage & 0.015 \\
\hline$\beta$ & returns to financial robustness & 0.25 \\
\hline$\rho$ & interest rate parameter & 0.05 \\
\hline$\tau_{\text {copy }}$ & price imitation rate & 0.1 \\
\hline$\tau_{\text {mutate }}$ & price mutation rate & \\
\hline$\mu$ & mutation factor & \\
\hline
\end{tabular}

Table 1: simulations' default parameters

Hence the firm can only determine an optimal input mix, not an optimal production level, on the basis of prices. In this sense, coordination through prices is incomplete and the equilibrium is indeterminate.

In our setting, indeterminacy on the firm's production level is reduced thanks to the financially constrained output function, which provides a cap on the production level of each firm. It is then a matter of basic accounting to realize that general equilibrium and financial stability are intrinsically linked. Indeed, unless there is a permanent inflow of money from the financial sector to the productive ones, the total financial capital held by firms must remain constant if production is to be sustained.

In a setting with constant returns, at a general equilibrium aggregate profits shall be zero in each sector, so that the financial capital and the production capacity remains constant. Hence, the equilibrium production and consumption as well as the corresponding distribution of financial capital can be reproduced period after period without additional inputs. Therefore, general equilibrium is a viable state of our dynamical system that induces stability of both the financial and the real spheres.

Away from equilibrium, a sector that makes positive profits sees its production capacity growing. Now, in absence of financial inflows from the financial to the production sphere, the profits of a sector are the losses of another. Hence the counterpart of these out-of-equilibrium profits shall be out-of-equilibrium losses in another sector whose production capacity must then shrink. Given the sectoral interdependencies in the production structure, such a situation is not viable as the shrinking of the unprofitable sector would eventually yield some rationing of the profitable one and a general decrease of production. The only 
ways forward are technological innovation (which we do not consider here) or inflow of additional financial capital, i.e the built-up of further leverage. In other words, disequilibrium is for us a symptom of financial fragility.

We will further analyze these relationships between real and financial instability below, but our initial inquiry is whether an economy can self-organize into a viable equilibrium state. That is, do economic agents' reaction to disequilibrium such as price or capacity changes, form a strong enough feedback mechanism to induce the convergence of the system towards equilibrium? A positive answer to this question is implicitly assumed in most of the existing economic theory. Previous simulation and analytical results of ours (see respectively Gintis (2007) and Gintis and Mandel (2012)) suggest that in a setting where competition is actually implemented through private updating of prices, evolutionary dynamics do lead the system to equilibrium. Here, the issue is revisited in a more realistic setting with intermediary production and financial constraints. It turns out that financial constraints actually matter. More precisely the stability of equilibrium and the dynamical regime crucially depend on the relative strength of resource and financial constraints. When the resource (labor) constraints dominate, the economy efficiently plays its role of allocation of scarce resources and equilibrium prevails. When financial constraints dominate, financial fragility is the key driver of the dynamics.

\subsection{Convergence properties}

Resources constraints in our economy are determined by the labor supply. Indeed, in absence of technological innovation, labor supply defines an upper bound on the aggregate production throughout time.

Conversely, given the leverage parameters $\phi$ and $\beta$, the financial constraints are defined by the initial wealth of firms and banks $a^{0} \in A$. These determine on the one hand, the initial stock of money and the initial production capacity. On the other hand, they will affect the capital of firms and banks created at runtime. Hence, they will determine the potential inflow of money in the production sector during a period (see section 2.5.3).

When these financial constraints are weak, i.e when the stock and the potential inflow of capital in the economy is large with respect to the labor resources, the model has very robust properties of convergence to equilibrium. To illustrate this point, we first consider a version of the model with three productive sectors $(N=3)$, fifty agents per sector $(M=50)$, and the remaining parameters set as in table 1 (in particular, the production network under consideration is symmetric). In this setting, the equilibrium price is equal to 1 for every good and the aggregate equilibrium production (resp. consumption) level is 100 (resp. $50)$. We initialize the model by drawing each price uniformly at random in $[0,2]$, allocating an initial wealth of 1 to each firm and of 100 to each bank. Then, resource constraints dominate as the equilibrium production level (100 units) is much less than what firms can finance without recourse to credit (300 units). Hence, as illustrated in the right panel of figure 1, total credit outstanding is negligible meaning that wages are mainly financed by firms' net worth. Con- 
straints on credit would anyhow be very weak: initial capital of banks is much greater than the recurrent financing needs of the production sector.

In this economy, the dynamics of the model are very clearcut: in about hundred periods, the mean private price of firms converges to its equilibrium value and the standard deviation of the price among firms become negligible (see figure 2) It is also the case that aggregate production and consumption reach their equilibrium values and that demand and supply balance each other (see left panel of figure 1). Hence the economy reaches equilibrium in approximately hundred periods and rests there for the remaining of the simulation.

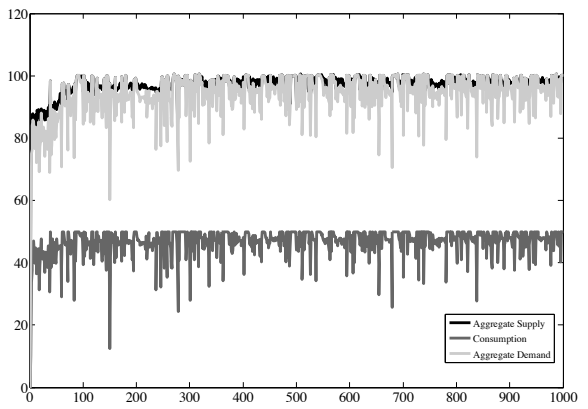

(a) Supply and Demand

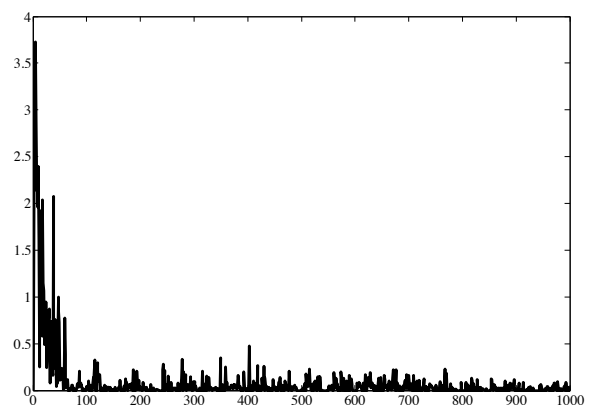

(b) total credit to firms

Figure 1: Markets

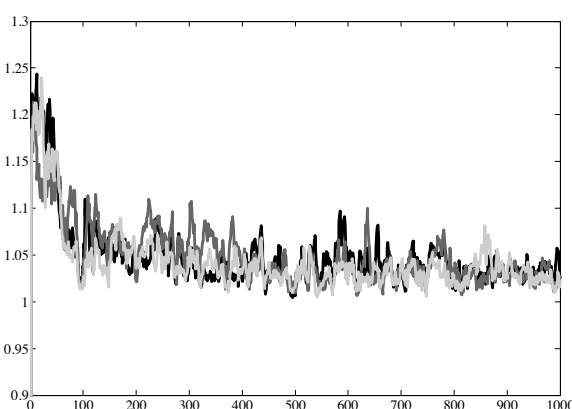

(a) Mean of prices in the 3 sectors

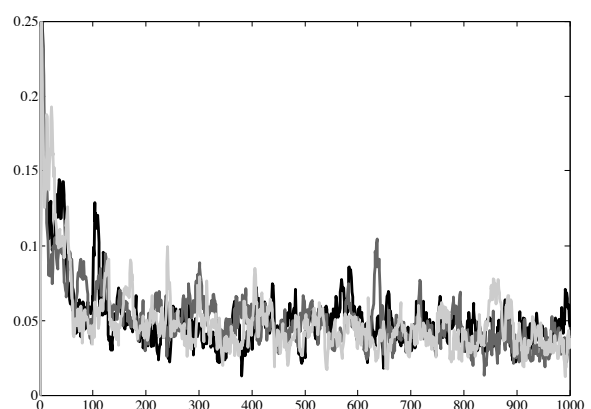

(b) standard deviation of prices in the 3 sectors

Figure 2: Prices

To provide a quantitative assessment of the convergence properties of the model, we perform 250 Monte-Carlo simulations where we let the number of sectors vary from 2 to 6 and randomly draw 50 distinct production networks (the other parameters being set as in table 1). To assess the results of these simulations, we use a concept of approximate equilibrium: 
Definition 2 The model is in an $\epsilon$-equilibrium in period $t$ if:

1. The euclidian distance between the mean selling price and the equilibrium price is less than $\epsilon$;

2. The standard deviation of prices is less than $\epsilon$;

3. The excess demand (i.e total production minus total consumption minus total intermediary consumption as determined in 2.4.) is less than $\epsilon$ times the total production.

We then measure for the 250 Monte-Carlo simulations the mean number of periods in which the model is in an $\epsilon$-equilibrium (with $\epsilon=0.1$ ). The results are reported in table 2 . Though the convergence time increases with the number of sectors, the model shows very robust properties of convergence to equilibrium. In the last 100 periods of the simulation, the model spends in average $80 \%$ of the time in equilibrium and for small number of sectors, the model is almost always in equilibrium.

\begin{tabular}{|c|c|c|c|c|c|c|}
\hline \# of sectors & 2 & 3 & 4 & 5 & 6 & mean \\
\hline mean \# of $\epsilon$-equilibria in periods 1-500 & 431 & 324 & 267 & 265 & 184 & 294 \\
\hline mean \# of $\epsilon$-equilibria in periods 100-500 & 384 & 314 & 261 & 262 & 184 & 281 \\
\hline mean \# of $\epsilon$-equilibria in periods 400-500 & 97 & 82 & 67 & 79 & 62 & 78 \\
\hline
\end{tabular}

Table 2: nb of periods in equilibrium

Hence, we do obtain converge to equilibrium when resource constraints dominate. The small source of volatility introduced by the random mutations in the price formation process do not get amplified into aggregate volatility nor fragility. These good convergence properties are a first contribution of the model: we extend to an economy with intermediary production, the results of Gintis (2007) about the convergence to general equilibrium of private prices under evolutionary dynamics. It is worth noting in this respect that the introduction of efficient dynamics for the allocation of goods in 2.4 is perfectly in line with the axiomatic characterization of exchange processes inducing evolutionary stability of equilibrium obtained in Gintis and Mandel (2012).

\subsection{Disequilibrium and financial fragility}

The previous picture of economic equilibrium and financial stability seems at odds with the results reported in Delli Gatti et al. (2010) where "prices are important determinants of profits, which in turn affect the accumulation of net worth and financial fragility. The financial vulnerability of an agent therefore is affected by the dynamics of prices." 
Yet, the economic environment considered in Delli Gatti et al. (2010) is a particular case of ours with two sectors and intermediary consumption by the second sector only, something that corresponds to $\alpha_{1}=1, \alpha_{2}=0.5$ and $\omega=\left(\begin{array}{ll}0 & 0 \\ 1 & 0\end{array}\right)$. The dynamics we consider are also very similar to these of Delli Gatti et al. (2010) but for the evolution of prices, which is purely random and exogenous in Delli Gatti et al. (2010) while it is endogenous and directed by evolutionary learning in our case. It is also the case that the sales of produced quantities at a purely random price in Delli Gatti et al. (2010) induce net inflows or outflows of money in the economy, whereas our model is stock-flow consistent as final consumption is entirely financed by wages and dividends.

One could therefore claim that it is the lack of stock-flow consistency and the exogenously imposed price volatility that induces financial fragility, networkbased financial accelerator mechanisms, bankruptcy avalanches and aggregate volatility in Delli Gatti et al. (2010). We shall show this is not the case.

Indeed, even small shocks on the the price system induce variation in sales and profits and eventually in firms' net worth. As soon as the financial constraints are binding, downward variations in net worth lead to a decrease of productive capacity. Decreased capacity in turn lowers the competitive pressure, so that prices start leaving the equilibrium paths. Rationing and losses follow, financial fragility increases and the way is paved for bankruptcy avalanches $\grave{a} l a$ Delli Gatti et al. (2010).

To illustrate this process, we consider a three-sector version of the model with parameters set as in Table 1 but where the initial net worth of firms is set equal to 0.25 and the one of banks equal to 2 (recall that these values also condition the capital of firms and banks created at runtime and hence the potential inflow of capital into the system). This economy is financially constrained, on the one hand because the aggregate production the firms can self-finance (75 units) is less than the equilibrium production (100 units) and on the other hand because the additional capital the banks can provide to the productive sector is also very limited. Indeed, as underlined in section 2.5.3, the only source of increase of the aggregate capital of the productive sector is the funding of new firms and the write-off of the claims on bankrupt firms, which are both financed by the banks.

As illustrated in figures 3 and 4, the first hundred periods of the simulation are rather similar to the ones leading to equilibrium in section 3.2. A slight difference being that in the very first periods, a series of bankruptcies induce a massive transfer of capital from the financial to the productive sector (see figure 5). It then seems that the productive sector reaches a level of capital compatible with the equilibrium production level. Yet this high capitalization is unsustainable as it is out of proportion with the financing flow that the financial sector can maintain towards the productive sector (see the right panel in figure 5). As a matter of fact, a shock to the price system around period 100 (see figure 4, most notably the right panel) triggers a temporary increase of the mean and of the standard deviation of the price of good 1, which induces a drop in demand (see figure 3) in sales, in profits and eventually in the net worth and 


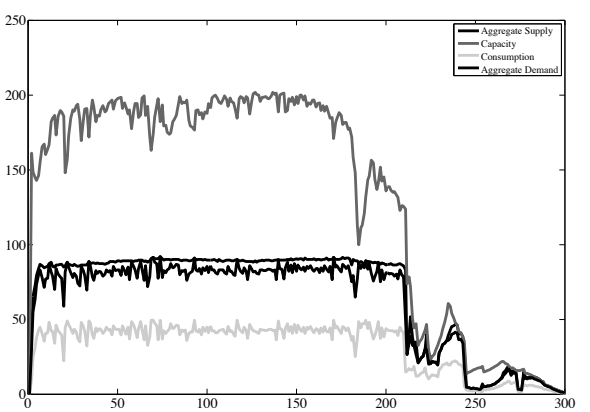

(a) Capacity, Supply and Demand

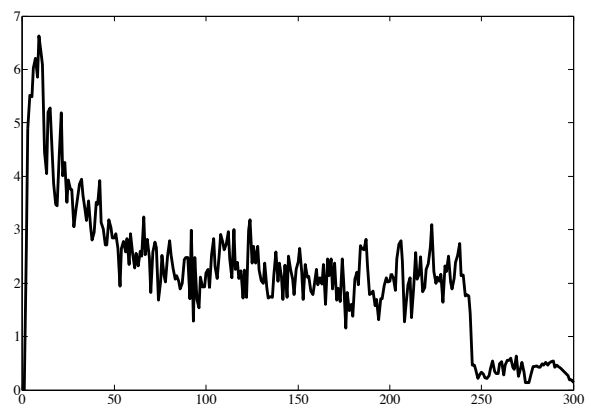

(b) credit from banks to firms

Figure 3: Markets

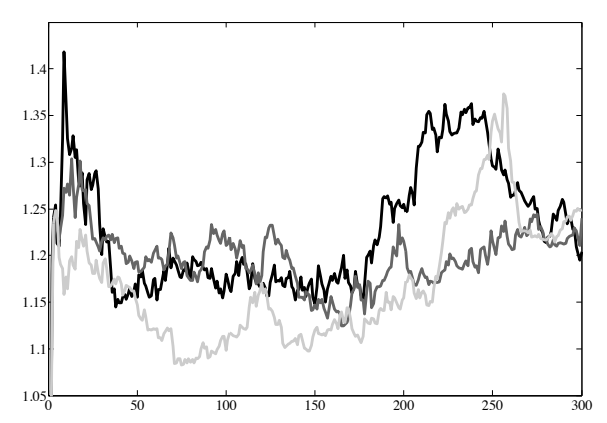

(a) Mean of prices in the 3 sectors

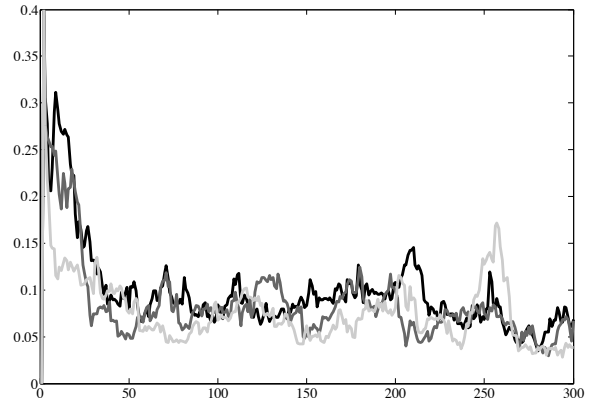

(b) Standard deviation of prices in the 3 sectors

Figure 4: Prices

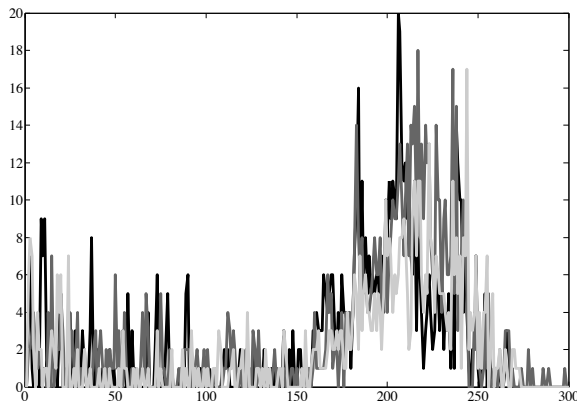

(a) Number of bankruptcies

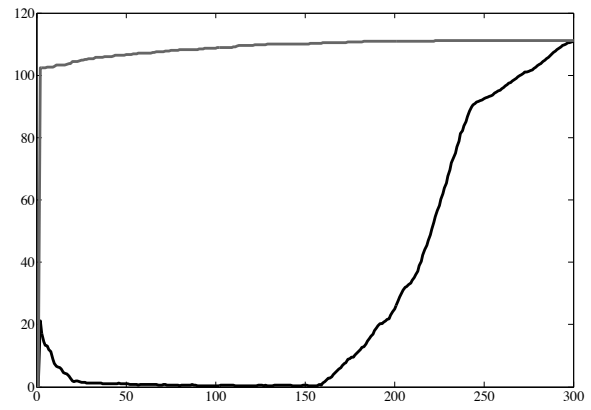

(b) Bank wealths (Black) and Money Stock (Gray)

Figure 5: Finance 
productive capacity of firms (see figure 6). Observing figure 5, one can remark that this loss of financial capital in the production sector is not compensated by a sizable inflow of capital from the financial to the production sector ; quite the contrary, the total net worth of banks is increasing. This is due to the fact that, as in Delli Gatti et al. (2010), the distribution of wealth among firms evolves during the simulation (see the evolution of the coefficient of variation in figure 6 ) and becomes much more dispersed. Larger firms face losses without going bankrupt and hence these losses are not passed to the financial sector (as it was the case at the beginning of the simulation when the size distribution of firms was uniform). Hence productive capacity does not recover, competition becomes less stringent and prices exit the equilibrium paths (see figure 4 from period 100 and onwards). As underlined in section 3.1, out-of-equilibrium, financial losses become structural. Consequently, the wealth of firm further decreases, interest rates increase with the financial fragility of borrowers and a positive feedback loop ensues which eventually leeds to a bankruptcy avalanche around period 170 (see figure 5).

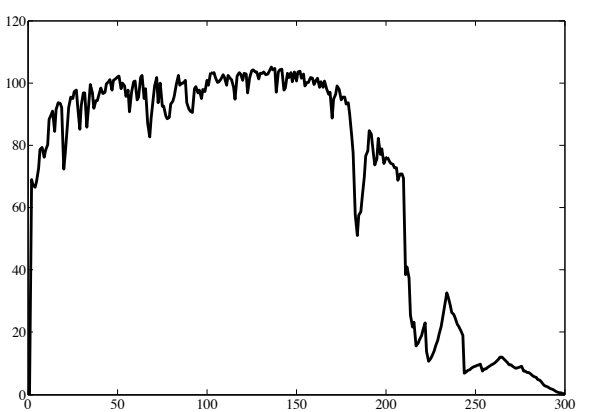

(a) Total firms' wealth

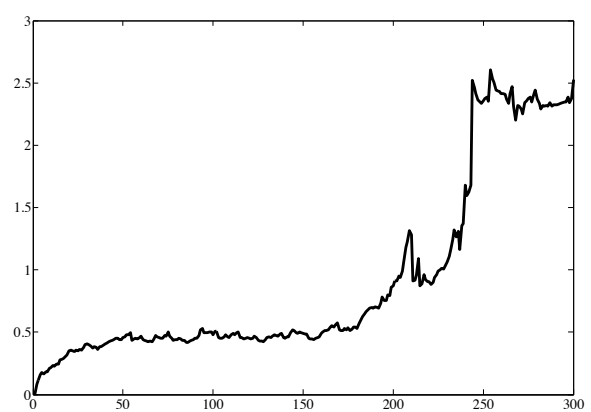

(b) Coefficient of variation for firms' wealth

Figure 6: Firms' wealth

The mechanisms at play are very similar to these described in Delli Gatti et al. (2010) "The bankruptcy of a borrower creates a negative externality because the bad debt recorded on the lender's balance sheet yields an increase of the interest rate charged to all the other borrowers. This is the starting point of the financial accelerator. If the surviving borrowers experience an increase of leverage due to the interest rate hike, the lender will react by raising the interest rate even further. Financial fragility will spread to the neighborhood and may spill over to the entire economy. An avalanche of bankruptcies may ensue." Yet, in our setting two other feedback mechanism are at play. First the decrease of financial capital and production capacity reduces the strength of competition and hence the stability of the price system. Second the sectoral interlinkages propagate rationing shocks throughout the system. These rationing shocks play the role of the idiosyncratic productivity shocks described in Acemoglu et al. (2012) as the drivers of aggregate volatility. 


\subsection{Financial constraints and phase transition}

The simulations' results reported above suggest that, depending on the strength of the financial constraints, the model exhibits two very different regimes. One is characterized by general equilibrium, low aggregate volatility and financial stability. The other is characterized by market disequilibrium, financial fragility and large aggregate volatility.

In order to test the assumption that financial constraints are the determinants of these two regimes, we run a series of 750 Monte-Carlo simulations (MC) where we let the default wealth of firms and banks vary (the other parameters being fixed as in table 1). More precisely, the default wealth of firms, which we denote by $w f$, takes the values $(0.1250,0.25,0.4,0.5,0.6,0.7,0.8,0.9,1,2)$, the one of banks, which we denote by $w b$, takes the values $(0.5,1,1.25,1.5,1.75$, $2,2.25,2.5,3,3.5,4,5,10,20,50)$ and we run $5 \mathrm{MC}$ over 500 periods for each possible combination of the variables $w f$ and $w b$. Figure 7 provides a graphical illustration of the results by plotting, as a function of the default wealth of firms and banks, the mean (over the five MC) number of periods for which the model is in an $\epsilon$-equilibrium (with $\epsilon=0,1$ ) and the mean volatility of GDP ${ }^{13}$.

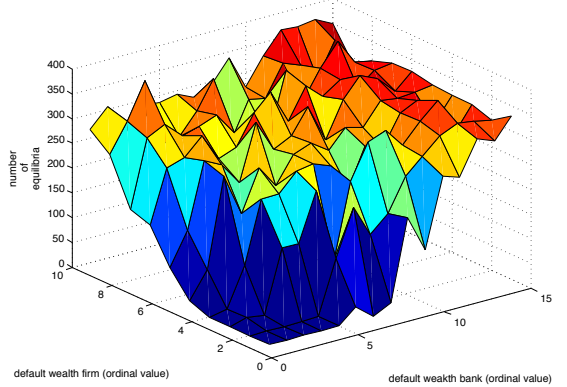

(a) Number of $\epsilon$-equilibria

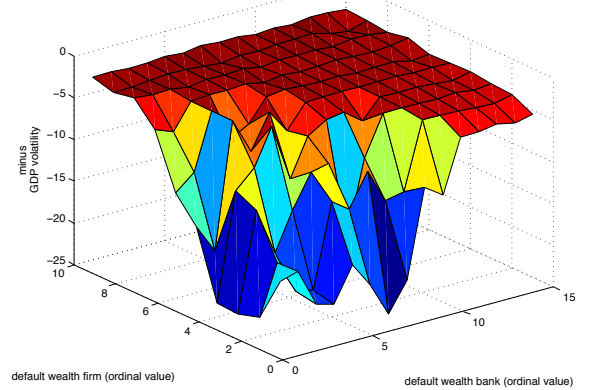

(b) minus GDP volatility

Figure 7: Phase transition under financial constraints

The hypothesis that the financial constraints govern the regime of the model is confirmed by the identification of a phase transition between the equilibrium and the disequilibrium states of the model, which materializes as a critical line in the $(w f, w b)$ plane. For small values of the pair $(w f, w b)$ the model almost never is in equilibrium and exhibits high volatility, for large values of the pair $(w f, w b)$ the model settles in equilibrium and exhibits low volatility. When the critical line is crossed, there is an abrupt transition between the two regimes. This abrupt transition between the two regimes can be well-approximated by a logistic function and suggests the existence of a phase-transition between equilibrium and non-equilibrium regimes. In this respect, our results are very similar

\footnotetext{
${ }^{13}$ The values on the $x$ and $y$ axis of figure 7 are ordinal, i.e 1 (resp. 15) corresponds to the smallest (reps. largest) value of wealth bank
} 
to those obtained in Gualdi et al. (2013): these authors show that phase transitions between equilibrium and disequilibrium can be driven by small shifts in firms' employment policy.

These results are robust with respect to change in the value of the other key financial parameter that is the interest rate. Additional simulations ran with a default interest rate varying between 0 and 6 percents yield a similar picture to the one presented in this section.

Additionally, we test the robustness of the results to changes in the dividend policy of the firm. The default financial policy of the firm is to distribute a dividend as soon as it makes a profit in the period (see 2.5.3). This very myopic behavior might be conductive to fragility as it prevents the firm from reconstituting a strong enough capital basis after it has been affected by a negative shock. In order to further investigate this point, we consider an alternative profit distribution policy which consists in distributing profits only if the current capital of the firm is greater than a benchmark, which is set equal to the initial value of the capital. The use of this alternative financial management rule does not affect the behavior of convergence to equilibrium reported in subsection 3.2 for parameter values that do not induce financial constraints. However in a setting with financial constraints, using the same parameter setting than in subsection 3.3 , the results are qualitatively different (see figure 8). The model now exhibits shifts between an equilibrium regime where prices stay around their equilibrium value and aggregate volatility is very low, and a disequilibrium regime where prices fluctuate away from their equilibrium value and aggregate volatility is high.

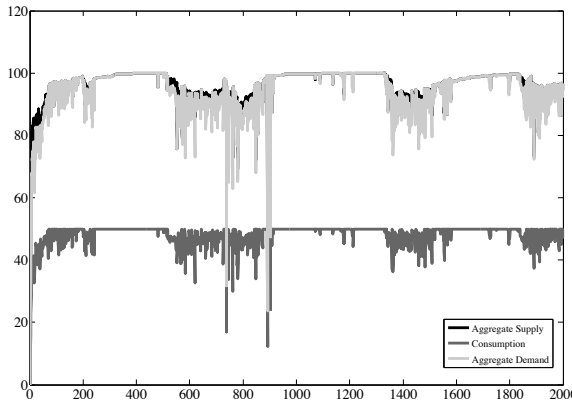

(a) Aggregate Demand and Supply

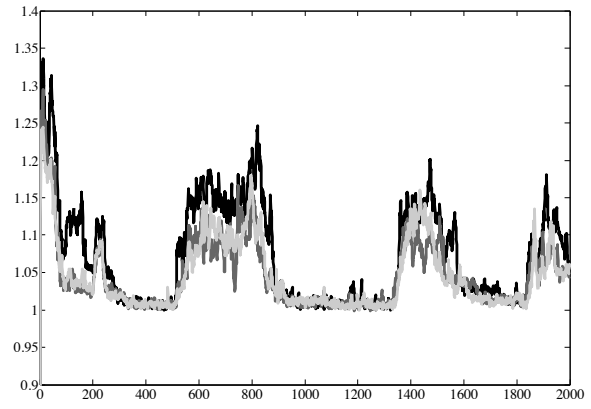

(b) Mean of prices in the 3 sectors

Figure 8: Markets

The main differences with the processes that lead to collapse in section 3.3 is that the productive sector is now more resilient: bankruptcy crisis are less acute and the economy eventually recovers. This is due to the fact that firms now have time to recapitalize themselves after a shock.

Overall, one observes long-term fluctuations between an equilibrium regime characterized by stability of price and production and a disequilibrium one char- 
acterized by price instability and financial fragility. This crisis regime is the carrier of aggregate volatility in the model. In other words, local disequilibrium in a decentralized price system and networked financial fragility are the micro-economic origins of aggregate volatility in our model. In the next section, we investigate the influence of the structure of the production network on the magnitude of these aggregate fluctuations.

\section{Network structure and aggregate volatility}

\subsection{Network structure}

The model introduced in the preceding sections allows to represent dynamic fluctuations between equilibrium and disequilibrium. In this section, we use it to analyze in a dynamical setting the relationships between network structure and aggregate volatilty put forward by Fisher and Vega-Redondo (2006), Battiston et al. (2007) and Acemoglu et al. (2012). In order to characterize network structures, we will mainly use degree distributions. In our framework, the degree of a sector $g$, defined as $\delta_{g}:=\sum_{h=1}^{N} \omega_{h, g}$, corresponds to the share of sector $g$ 's output in the input supply of the entire economy. The production network can be characterized among others in terms of:

- The mean of the degree sequence

$$
\bar{\delta}:=\frac{1}{N} \sum_{g=1}^{N} \delta_{g} ;
$$

- The coefficient of variation of the degree sequence

$$
\xi_{1}:=\frac{\sqrt{\sum_{g=1}^{N}\left(\delta_{g}-\bar{\delta}\right)^{2}}}{\sqrt{N \bar{\delta}}},
$$

which is used as a first-order measure of the asymmetry of the network in Acemoglu et al. (2012);

- The second order interconnectivity coefficient

$$
\xi_{2}:=\sum_{g=1}^{N} \sum_{h \neq g} \sum_{k \neq g, h} \omega_{h, g} \omega_{k, g} \delta_{h} \delta_{k},
$$

introduced by Acemoglu et al. (2012) to measure the extent to which sectors with high degrees are interconnected to one another through common suppliers.

We investigate the relationship between network structure, disequilibrium and aggregate volatility for three types of networks: for the first type the degree distribution is drawn uniformly, for the second it is drawn according to a 
lognormal distribution and for the third it is drawn according to a power law/ Pareto distribution. More precisely, the networks are constructed as follows. We draw a degree sequence according to the prescribed distribution (relying on Clauset et al. (2009) for power law distributions). The sequence is then normalized (so as to ensure that the sum of input shares will sums to one in every sector) and the network is constructed using a directed version of the configuration model (see Newman et al., 2001).

For each type of networks, we run 125 Monte-Carlo simulations where we let the parameters of the degree distributions vary so as to generate a sample of networks with sufficiently heterogeneous coefficients of variation and of interconnectivity (the number of sectors is fixed equal to 10, the number of agents per sector equal to 25 , initial wealth of firms to 0.5 , initial wealth of banks to 20 and other parameters are set as in table 1 ).

We then analyze the results of these simulations along three dimensions: first the relation between network structure, disequilibrium and aggregate volatility, then the relation between aggregate volatility and (i) second order interconnectivity and (ii) the presence of fat tails.

\subsection{Equilibrium and volatility}

Our results first of all confirm the relation between disequilibrium and aggregate volatility established in the previous section. As illustrated in figure $9 a$ and in table 3 (first column), the time spent out of $\epsilon$-equilibrium ${ }^{14}$ is a very good predictor of the volatility of GDP, independently of the network structure ${ }^{15}$.

Our central concern then is the impact of the network's structure on aggregate volatility. In this respect, our results confirm the findings of Acemoglu et al. (2012) about the positive impact of network's asymmetry (measured by the coefficient of variation of the degree sequence) on aggregate volatility. As illustrated in figure $9 b$ and table 3 (second column) independently of the type of network considered (uniform, lognormal, power law), we find a very robust statistical relation between the coefficient of variation of the production network and GDP volatility: volatility increases exponentially with the coefficient of variation.

A similarly monotone relationship exists between the coefficient of variation and the time spent in equilibrium (see figure 10a). In line with the findings of the preceding section, this suggests that the impact of the network's structure on aggregate volatility is mediated by disequilibrium. This hypothesis is further backed by the fact that the impact of the coefficient of variation is much lower when one controls for the number of periods spent in equilibrium (see third column in table 3 ).

Overall, our results confirm those put forward in theorem 2 of Acemoglu et al. (2012). We shall also argue that they have a stronger empirical content

\footnotetext{
${ }^{14} \epsilon$ is set equal to 0.1 throughout this section

${ }^{15}$ We restrict attention to simulation runs spending less than $80 \%$ of the time in equilibrium to correct for the heteroscedasticity brought about by limited dependence: the volatility and its variance decrease massively when the system spends the bulk of his time in equilibrium.
} 
as we measure the actual volatility of GDP in a dynamical setting rather than its asymptotic properties in a static setting. Additionally, our results about the number of equilibria show that the network structure has a significative impact on the average residence time in equilibrium and hence somehow transcend those of Acemoglu et al. (2012) as they show that the network structure matters even before equilibrium is established, which is the starting point of Acemoglu et al. (2012). Moreover, we do not need to resort to exogenous productivity shocks to explain the origin of aggregate fluctuations. In our setting, the origin of fluctuations can be traced to the microscopic shocks to the price system that come along evolutionary dynamics and that bring about disequilibrium and volatility when they are amplified by financial accelerator mechanisms.

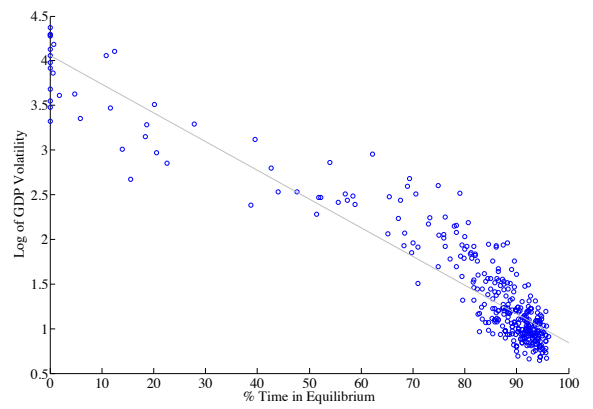

(a) Log GDP volatility vs Time in Equilibria

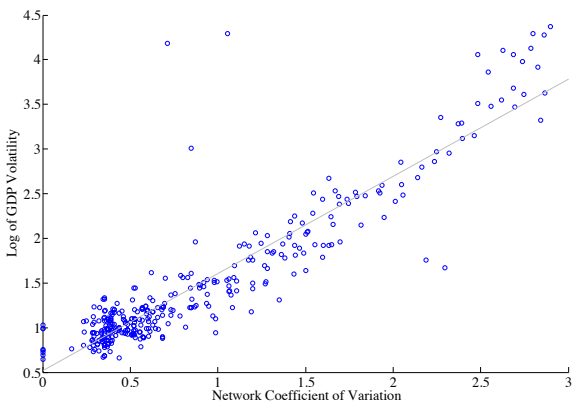

(b) Log GDP volatility vs Coeff. Variation

Figure 9: Determinants of GDP volatility

Log Vol. GDP Log Vol. GDP Log Vol.GDP

\begin{tabular}{lccc}
\hline (Intercept) & $3.84^{* * *}$ & $0.52^{* * *}$ & $3.08^{* * *}$ \\
& $(0.06)$ & $(0.03)$ & $(0.20)$ \\
coeff. var & & $1.09^{* * *}$ & $0.30^{* * *}$ \\
& & $(0.025)$ & $(0.08)$ \\
\% Time in equi. & $-2.4^{* * *}$ & & $-2.02^{* * *}$ \\
& $(0.1)$ & & $(0.15)$ \\
\hline$R^{2}$ & 0.85 & 0.84 & 0.88 \\
Num. obs. & 76.00 & 375.00 & 76.00 \\
\hline${ }^{* * *} p<0.01,{ }^{* *} p<0.05,{ }^{*} p<0.1$ & &
\end{tabular}

Table 3: GDP Volatility and Equilibrium 


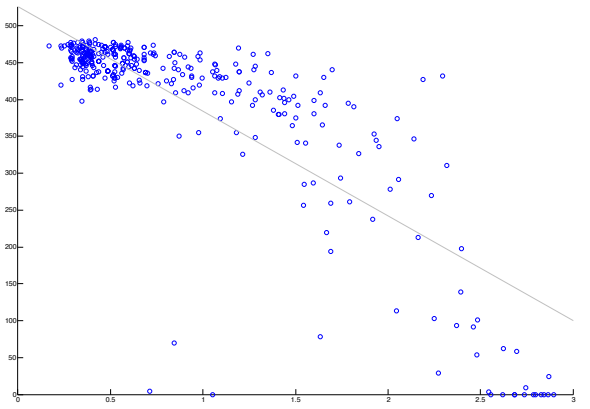

(a) Time in Equilibria vs Coeff. Variation

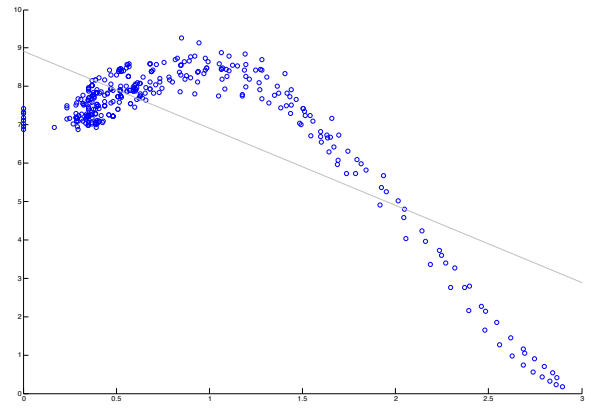

(b) Coeff. Connect vs Coeff. Var

Figure 10: Impact of the coefficient of variation

\subsection{Second order interconnectivity and aggregate volatil- ity}

We then focus on the impact of second order interconnectivity on volatility. The coefficient of second order interconnectivity measures the extent to which sectors with high degrees (those that are major suppliers to other sectors) are interconnected to one another through common suppliers. Acemoglu and al (2012) emphasize the fact that the second-order interconnectivity can have a significant positive impact on volatility. We also find that the second order interconnectivity has a statistically significant impact on volatility but surprisingly, we find that the effect is negative and hence opposite to the one identified by Acemoglu and co-authors (see first column in table 4)

Presumably, this difference is to a large extent explained by the fact that Acemoglu and co-authors implicitly treat the coefficients of variation and of interconnectivity as independent whereas, as illustrated in figure 10b, they are in fact strongly (though not linearly) correlated. Yet, the negative impact of the interconnectivity coefficient remains significant (though weaker) even when the influence of the coefficient of variation is corrected for (see second column in table 4).

A possible explanation is that, in our setting, the influence of interconnectivity on the transmission of shocks between sectors emphasized by Acemoglu and co-authors could be more than compensated by the fact that increased interconnectivity implies larger markets for intermediary consumption and hence further price-stabilizing competition. Indeed the latter effect might increase the stability of equilibrium and hence play an important role in our setting where volatility is closely related to out-of-equilibrium dynamics. This effect can't be accounted for in an equilibrium model where out-of-equilibrium dynamics are not represented. 


\subsection{Heavy tails and aggregate volatility}

There has been a lot of emphasis in the recent literature on the role of fat tails in the propagation of shocks (see in particular Gabaix, 2011; Acemoglu et al., 2012). In particular, in corollary 1 of Acemoglu et al. (2012) it is shown that if the degree distribution of the production network follows a power law (and hence is fat tailed), the coefficient of variation of the distribution is such that the decay of aggregate volatility is slow. Hence fat tails are said to have a positive impact on volatility. One could however argue that this impact of volatility is due to the fact that the distribution has a large coefficient of variation (that depends on the first and second moments of the distribution) rather than on the presence of fat tails per se (that are usually associated with large third and/or fourth moments). The effects are hard to disentangle analytically but in our setting where we consider both uniform networks and heavy-tail ones (lognormal and power law), it suffices to test the impact of the type of network on aggregate volatility while controlling for the impact of the coefficient of variation.

As illustrated in table 4 (see third and fourth columns) the presence of fat tails (measured either via the skewness of the degree sequence or by a binary variable equal to one if and only if the degree distribution is of a fat-tailed type) has a statistically significant effect on aggregate volatility even when controlling for the impact of the coefficient of variation. However, this effect is negative. This strongly suggests that it is indeed because of their high variance rather than because of their fat tail that fat-tailed degree distributions have a positive impact on volatility. As for the negative impact of fat tails, for a given coefficient

\begin{tabular}{lcccc}
\hline & Log Vol. GDP & log Vol. GDP & Log Vol.GDP & Log Vol.GDP \\
& & & & \\
\hline (Intercept) & $3.92^{* * *}$ & $1.20^{* * *}$ & $0.49^{* * *}$ & $-0.56^{* * *}$ \\
& $(0.11)$ & $(0.13)$ & $(0.03)$ & $(0.03)$ \\
coeff. var & & $0.93^{* * *}$ & 1.20 & $1.12^{* * *}$ \\
& & $(0.03)$ & $(0.04)$ & $(0.03)$ \\
coeff. connect & $-0.34^{* * *}$ & $-0.08^{* * *}$ & & \\
skewness & $(0.01)$ & $(0.01)$ & $-0.08^{* * *}$ & \\
fat-tail binary & & & $(0.02)$ & $-0.11 * * *$ \\
& & & & $0.04)$ \\
\hline$R^{2}$ & 0.59 & 0.85 & 0.85 & 0.84 \\
Num. obs. & 375.00 & 375.00 & 375.00 & 375.00 \\
\hline${ }^{* * *} p<0.01,{ }^{* *} p<0.05,{ }^{*} p<0.1$ & & &
\end{tabular}

Table 4: GDP Volatility and Network Structure 
of variation, a tentative explanation is that the presence of small sectors tends to decrease the skewness and that small actors being more fragile, their presence might also have a positive impact on aggregate volatility.

\section{Conclusion}

This paper confirms previous findings (see Gintis, 2007; Gintis and Mandel, 2012) that evolutionary dynamics applied to decentralized systems of private prices have strong properties of convergence towards general equilibrium. We have built on these properties to equip the standard real-business cycle model à la Long and Plosser (1983) with agent-based dynamics. In particular, we have introduced financially constrained production and a primitive financial architecture à la Delli Gatti et al. (2010). We have revisited in this framework the relationships between equilibrium, financial fragility and aggregate volatility.

Our first contribution is to show that the stability of equilibrium and the dynamical regime of the economy crucially depend on the relative strength of resource and financial constraints. When financial constraints are weak, the economy behaves as an efficient mechanism for the allocation of scarce resources thanks to the emergence of a general equilibrium. When financial constraints bite, i.e outside a barter economy, there is a correspondence and a positive feedback loop between disequilibrium and financial fragility: small price variations can trigger financial imbalances that get amplified by financial accelerator mechanisms, these imbalances lead to reduced productive capacity and competitive pressure, less competition favors out-of-equilibrium excursions of the price system, what leads to additional financial imbalances. These findings allow to explicit the link between the theory of financial fragility (see Greenwald and Stiglitz, 1993; Delli Gatti et al., 2010, and earlier contributions) and general equilibrium.

Our second contribution is to provide dynamic and endogenous foundations to the findings of Acemoglu et al. (2012) on the network origins of aggregate fluctuations. In our dynamical setting, we can measure aggregate volatility along dimensions that are consistent with empirical observations, i.e through time rather than as a static response to a distribution of shocks. We can also trace the origin of aggregate fluctuations to the microscopic shocks to the price system that come along evolutionary dynamics and that bring about disequilibrium and volatility when they are amplified by financial accelerator mechanisms. More generally, we show that volatility materializes mainly out-of-equilibrium and that the network structure affects aggregate volatility because it impacts the speed of convergence to and the stability of equilibrium.

Though the financial constraints play a central role in our analysis, our representation of the financial system is rather primitive. There are only shortlived financial assets, no precautionary savings, no investment. There is no interbank clearing mechanism, no bound on banks' leverage, no monetary policy. These gaps to be filled provide elements of a research program that could aim at a better understanding of the transmission channel of monetary policy thanks 
to refined models of the financial system.

\section{References}

Acemoglu, D., Carvalho, V. M., Ozdaglar, A., and Tahbaz-Salehi, A. (2012). The network origins of aggregate fluctuations. Econometrica, 80(5):19772016.

Arrow, K. J. (1964). The role of securities in the optimal allocation of riskbearing. The Review of Economic Studies, 31(2):91-96.

Bak, P., Chen, K., Scheinkman, J., and Woodford, M. (1993). Aggregate fluctuations from independent sectoral shocks: self-organized criticality in a model of production and inventory dynamics. Ricerche Economiche, 47(1):3-30.

Battiston, S., Delli Gatti, D., Gallegati, M., Greenwald, B., and Stiglitz, J. E. (2007). Credit chains and bankruptcy propagation in production networks. Journal of Economic Dynamics and Control, 31(6):2061-2084.

Battiston, S., DelliGatti, D., Gallegati, M., Greenwald, B., and Stiglitz, J. E. (2012a). Liaisons dangereuses: Increasing connectivity, risk sharing, and systemic risk. Journal of Economic Dynamics and Control, 36(8):1121 - 1141.

Battiston, S., Puliga, M., Kaushik, R., Tasca, P., and Caldarelli, G. (2012b). Debtrank: too central to fail? financial networks, the FED and systemic risk. Scientific reports, 2.

Clauset, A., Shalizi, C. R., and Newman, M. E. (2009). Power-law distributions in empirical data. SIAM review, 51(4):661-703.

Dawid, H., Gemkow, S., Harting, P., and Neugart, M. (2012). Labor market integration policies and the convergence of regions: the role of skills and technology diffusion. Journal of Evolutionary Economics, 22(3):543-562.

Dawid, H., Gemkow, S., Harting, P., van der Hoog, S., and Neugart, M. (2011). The eurace@ unibi model: An agent-based macroeconomic model for economic policy analysis. Technical report, Working paper. Universität Bielefeld.

Debreu, G. (1959). Theory of value: An axiomatic analysis of economic equilibrium. Number 17. Yale University Press.

Delli Gatti, D., Gallegati, M., Greenwald, B., Russo, A., and Stiglitz, J. E. (2010). The financial accelerator in an evolving credit network. Journal of Economic Dynamics and Control, 34(9):1627-1650.

Delli Gatti, D., Guilmi, C. D., Gaffeo, E., Giulioni, G., Gallegati, M., and Palestrini, A. (2005). A new approach to business fluctuations: heterogeneous interacting agents, scaling laws and financial fragility. Journal of Economic Behavior \& Organization, 56(4):489-512. 
Dosi, G., Fagiolo, G., Napoletano, M., and Roventini, A. (2013). Income distribution, credit and fiscal policies in an agent-based keynesian model. Journal of Economic Dynamics and Control, 37(8):1598-1625.

Dosi, G., Fagiolo, G., and Roventini, A. (2010). Schumpeter meeting keynes: A policy-friendly model of endogenous growth and business cycles. Journal of Economic Dynamics and Control, 34(9):1748-1767.

Dupor, B. (1999). Aggregation and irrelevance in multi-sector models. Journal of Monetary Economics, 43(2):391-409.

Edwards, P. N. (2010). A Vast Machine: Computer Models, Climate Data, and the Politics of Global Warming (Infrastructures). The MIT Press.

Eisenberg, L. and Noe, T. H. (2001). Systemic risk in financial systems. Management Science, 47(2):236-249.

Fisher, E. and Vega-Redondo, F. (2006). The linchpins of a modern economy. In AEA Annual Meeting, Chicago, IL.

Fisher, F. M. (1989). Disequilibrium foundations of equilibrium economics, volume 6. Cambridge University Press.

Gabaix, X. (2011). The granular origins of aggregate fluctuations. Econometrica, 79(3):733-772.

Geanakoplos, J., Axtell, R., Farmer, J. D., Howitt, P., Conlee, B., Goldstein, J., Hendrey, M., Palmer, N. M., and Yang, C.-Y. (2012). Getting at systemic risk via an agent-based model of the housing market. American Economic Review, 102(3):53-58.

Gintis, H. (2007). The dynamics of general equilibrium. Economic Journal, 117(523):1280-1309.

Gintis, H. and Mandel, A. (2012). The stability of walrasian general equilibrium. Documents de travail du Centre d'Economie de la Sorbonne 12065, Université Panthéon-Sorbonne (Paris 1), Centre d'Economie de la Sorbonne.

Greenwald, B. C. and Stiglitz, J. E. (1993). Financial market imperfections and business cycles. The Quarterly Journal of Economics, 108(1):77-114.

Gualdi, S., Tarzia, M., Zamponi, F., and Bouchaud, J.-P. (2013). Tipping points in macroeconomic agent-based models. arXiv preprint arXiv:130\%.5319.

Horvath, M. (1998). Cyclicality and sectoral linkages: Aggregate fluctuations from independent sectoral shocks. Review of Economic Dynamics, 1(4):781808 .

LeBaron, B. and Tesfatsion, L. (2008). Modeling macroeconomies as openended dynamic systems of interacting agents. American Economic Review, 98(2):246-50. 
Long, John B, J. and Plosser, C. I. (1983). Real business cycles. Journal of Political Economy, 91(1):39-69.

Mandel, A. (2012). Agent-based dynamics and the general equilibrium model. Complexity Economics, 1(1):105-121.

Mandel, A., Jaeger, C., Fürst, S., Lass, W., Lincke, D., Meissner, F., PabloMarti, F., and Wolf, S. (2010). Agent-based dynamics in disaggregated growth models. Documents de travail du Centre d'Economie de la Sorbonne 10077, Université Panthéon-Sorbonne (Paris 1), Centre d'Economie de la Sorbonne.

Napoletano, M., Dosi, G., Fagiolo, G., and Roventini, A. (2012). Wage formation, investment behavior and growth regimes: An agent-based analysis. Revue de l'OFCE, (5):235-261.

Newman, M. E., Strogatz, S. H., and Watts, D. J. (2001). Random graphs with arbitrary degree distributions and their applications. Physical Review E, 64(2):026118.

Walras, L. (1874). Elements of Pure Economics. George Allen and Unwin, London.

Wolf, S., Fuerst, S., Mandel, A., Lass, W., Lincke, D., Pablo-Marti, F., and Jaeger, C. (2013). A multi-agent model of several economic regions. Environmental Modelling and Software, 44:25 - 43. 